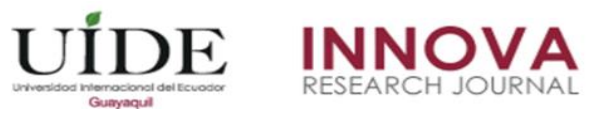

INNOVA Research Journal, ISSN 2477-9024

(Marzo, 2018). Vol. 3, No.3 pp. 69-83

DOI: https://doi.org/10.33890/innova.v3.n3.2018.438

URL: http://revistas.uide.edu.ec/index.php/innova/index

Correo: innova@uide.edu.ec

\title{
Impacto de la salida del tratado ATPDEA en la exportación de brócoli del Ecuador a los EEUU. Caso comparado Ecuador - Guatemala (2010 - 2016
}

\author{
Impact of the exit of the ATPDEA treaty on the export of broccoli from \\ Ecuador to the USA. Ecuador - Guatemala compared case (2010 - 2016)
}

Jorge Antonio Ruso León

Digna Priscila Villamar Ortiz

Universidad Agraria del Ecuador, Ecuador

Autor Para Correspondencia: jruso@uagraria.edu.ec, pvillamar@uagraria.edu.ec

Fecha De Recepción: 11 De Octubre 2017 - Fecha De Aceptación: 15 De Febrero De 2018

Resumen: La producción y exportación de brócoli en el Ecuador es fuente de empleo e importantes ingresos para el país. Considerando el potencial impacto negativo que podría tener sobre esta industria la pérdida de las preferencias arancelarias que proveía el tratado atpdea a causa de la decisión del gobierno de abandonarlo, esta investigación se planteó, comprobar sí existió tal impacto o si éste fue evitado gracias a la aplicación de las políticas implementadas para contrarrestarlo. Mediante el uso de la metodología cuantitativa, documental y de campo, se procedió, aplicando la observación directa de los registros del banco central del Ecuador y el banco de Guatemala, a recopilar, comparar y correlacionar las exportaciones de brócoli del Ecuador y Guatemala al mercado de los eeuu, así como las del Ecuador a japón (principal mercado) y al resto del mundo, en el período 2010-2016, observándose los siguientes resultados: las exportaciones de brócoli del Ecuador a los eeuu mantienen una tendencia creciente durante el período con una única caída el 2013 e inmediata recuperación del 2014 en adelante, similar tendencia y evolución muestran las exportaciones al japón, mientras que las exportaciones al resto del mundo presentan una evolución irregular con tendencia decreciente. Por su parte, al comparar con las exportaciones guatemaltecas al mercado de los eeuu, se constata que éstas decrecen sostenidamente del 2012 en adelante mostrando un desempeño muy pobre respecto a las del Ecuador a pesar de su pertenencia al cafta, concluyéndose que el sector en el Ecuador apenas fue afectado por la medida del gobierno. Palabras Clave: ATDPEA; exportaciones; brócoli; exenciones; aranceles

Abstract: The production and export of broccoli in Ecuador is a source of employment and significant income for the country. Considering the potential negative impact on the industry of the loss of tariff preferences provided by the atpdea treaty because of the government's decision to abandon it, this investigation was made to know, whether such an impact existed or whether it was avoided because of the implementation of policies designed to counteract it. Using the quantitative, documentary and field methodology, the direct observation of the records of the central bank of Ecuador and the bank of Guatemala was carried out to compile, compare and correlate the exports of broccoli from Ecuador and Guatemala to the us market and from Ecuador to japan (main market) and to the rest of the world in the period 2010-2016, being observed the following results: exports of broccoli from Ecuador to the us continue to increase during the period with a single drop in 2013 and immediate recovery from 2014 onwards, a similar trend and evolution show exports to 
japan, while exports to the rest of the world show an irregular evolution with a decreasing trend. On the other hand, when comparing with the Guatemalan exports to the us market, it is observed that these declined steadily from 2012 onwards, showing a very poor performance compared to Ecuador despite its membership in cafta, concluding that the sector in the Ecuador was hardly affected by the government measure.

Key Words: ATDPEA; exports; broccoli; exemptions; tariffs

\section{Introducción}

La producción de brócoli en el Ecuador, desde los noventa mantiene un constante crecimiento a tenor de lo que expresa PROECUADOR (2014), asimismo las exportaciones de este producto se constituyen en un renglón importante dentro del grupo de las exportaciones no petroleras no tradicionales en nuestro país.

Esta industria está en su totalidad ubicada en la Sierra, siendo la provincia de Cotopaxi el mayor productor. Ecuador es el primer exportador de brócoli en Sudamérica, a nivel latinoamericano sus principales competidores son, según Cámara de Industrias y Producción (2011), México y Guatemala. Teniendo en cuenta a PROECUADOR (2017) el 65\% del brócoli ecuatoriano se destina a la exportación.

Según Ministerio de Comercio Exterior (2017), EEUU, solo por detrás de Japón, es uno de los principales mercados para el brócoli ecuatoriano, producto que hasta julio del 2013 (El Comercio, 2013) disfrutó de las exenciones arancelarias otorgadas por la adhesión de Ecuador a la Ley de Preferencias Arancelarias Andinas y Erradicación de la Droga (ATPDEA, por sus siglas en inglés Andean Trade Promotion and Drug Eradication Act).

La ATPDEA, indica Ecuavisa (2013), fue una ley aprobada por el congreso norteamericano que otorgaba beneficios a los productos que llegan desde la zona andina, estos beneficios se circunscribían básicamente a reducción de aranceles. El objetivo de este sistema de preferencias era fortalecer las actividades legales de los países andinos, como alternativas al tráfico y producción de cocaína (Falconí \& Oleas, 2013).

En el diario El Comercio (2013) se refiere que, en Jul/2013 el gobierno del Econ. Rafael Correa decidió eliminar unilateralmente las preferencias arancelarias del ATPDEA con lo cual se perdieron las exenciones de que disfrutaban el brócoli y otros productos que se exportaban al mercado estadounidense como atún, flores, etc.

La decisión de eliminar las preferencias arancelarias del ATPDEA, por parte del gobierno ecuatoriano a mediados del año 2013, fue causada porque no se llegó a un acuerdo con Estados Unidos para mantener la Base de Manta donde operaban soldados ecuatorianos en conjunto con asesores norteamericanos en la lucha antidrogas Ekos (2013), además de otras consideraciones relacionados con temas de soberanía política. Esta decisión impactó en diversos sectores productivos ecuatorianos que gozaban de preferencias arancelarias en las exportaciones realizadas a los Estados Unidos, uno de ellos fue la exportación de brócoli, que, gracias al ATPDEA, ingresaba a Estados Unidos con cero aranceles. 
Con la eliminación del tratado, los productos beneficiados perderían competitividad en el mercado norteamericano al verse obligados a entrar a ese país con precios que los pondrían en notoria desventaja respecto a la competencia, esta situación sería desastrosa para los productores y exportadores ecuatorianos que deberían con urgencia reorientar sus exportaciones hacia otros destinos perdiéndose, entretanto, importantes entradas de divisas al país y miles de empleos (El Telégrafo, 2013).

En un artículo de Ecuavisa (2013) se cita un informe de la Federación de Exportadores donde se asegura que el producto más afectado por la salida del ATPDEA es el atún en conserva, seguido por las flores y el brócoli. En el cual se indica que, si estos productos hubieran pagado arancel durante los dos últimos años $(2011$ - 2012), el atún habría de cancelar cerca de 13 millones de dólares, las rosas 5,7 millones y el brócoli, alrededor de tres.

El diario El Telégrafo (2013) expone que, según datos del Centro de Estudios y Análisis de la Cámara de Comercio de Quito, al no haber un acuerdo comercial y no renovarse las preferencias, algunos productos, como el brócoli, pagarían un arancel de 14,9\%. Una vez cancelado el acuerdo el gobierno nacional estableció un conjunto de mecanismos de compensación para apoyar a los afectados con esta medida consistente en la devolución de los aranceles que deberían pagar por los productos exportados a EEUU, no obstante, se hace imprescindible conocer en qué medida se han afectado los productores y exportadores de brócoli, en tanto que, este producto era, entre los regulados por el ATPDEA, el tercero de mayor volumen de entradas en el país norteamericano según (Ekos, 2013).

El mecanismo en concreto que estableció el gobierno para compensar a los exportadores consistió en la creación del certificado de abono tributario, de manera tal que el Gobierno Nacional cubriría el arancel que deben pagan los exportadores y de esa manera no se encarece el producto para el importador de Estados Unidos (El Telégrafo, 2013).

El costo del mecanismo de compensación que pondría en funcionamiento el gobierno para cancelar el arancel que deberían pagar los exportadores sería de 23 millones de dólares, monto que sería sencillo de afrontar para el país, según expresó el propio Presidente Rafael Correa en (ECUADORINMEDIATO.com, 2013).

Es cardinal, a tenor, de la importancia del brócoli como renglón exportable no petrolero y del mercado norteamericano como destino principal para éste y otros productos, determinar si la actual evolución que registra la exportación de brócoli a EEUU se ha visto afectada por el abandono del ATPDEA o si, por el contrario, la política adoptada por el gobierno nacional orientada a apoyar al sector exportador de esta hortaliza ha sido efectiva en evitar los potenciales efectos negativos derivados de la salida del tratado.

El problema que plantea resolver la presente investigación se centrará en evaluar el impacto de la medida sobre productores y exportadores. Para ello se tomará como punto de comparación tanto la evolución histórica de las exportaciones a los EEUU, Japón y resto del mundo del producto previas y posteriores a la decisión de la ruptura del acuerdo y las exportaciones del mismo producto que hacia el mercado norteamericano realiza Guatemala que es uno de los proveedores latinoamericanos más importantes de la hortaliza en el mercado de 
EEUU, a partir de lo que se determine se podrá trazar una línea base para recomendar acciones correctivas y preventivas que promuevan el fortalecimiento del sector productor y exportador de brócoli ecuatoriano.

Por ello, se debe contar con un análisis que permita determinar: ¿Cómo impactó sobre la exportación de brócoli del Ecuador a los EEUU en comparación con las mismas al Japón, al resto del mundo y con las de Guatemala al mismo mercado en el periodo 2010 - 2016, la decisión del gobierno ecuatoriano del Econ. Rafael Correa de eliminar unilateralmente las preferencias arancelarias del ATPDEA?

El objetivo general que dará respuesta al problema planteado será: Comparar las exportaciones de brócoli del Ecuador al mercado de EEUU versus las realizadas al Japón, al resto del mundo y respecto a las ejecutadas por Guatemala al mismo mercado norteamericano en el periodo 2010 - 2016, considerando la influencia de la decisión del gobierno ecuatoriano de eliminar la preferencia arancelaria del ATPDEA en el año 2013, para el efecto, se deben responder los siguientes objetivos específicos:

- Determinar la evolución de las exportaciones de brócoli del Ecuador hacia los mercados de EEUU, Japón y al resto del mundo de ese producto.

- Determinar la evolución de las exportaciones de brócoli de Guatemala hacia el mercado de EEUU.

- Establecer el comportamiento de las exportaciones de brócoli del Ecuador hacia los EEUU, Japón y resto del mundo para determinar su evolución y potenciales correlaciones.

- Establecer, comparar y correlacionar las exportaciones de brócoli del Ecuador y Guatemala hacia los EEUU para comprobar el potencial efecto de la salida del ATPDEA y la efectividad de las medidas tomadas por el gobierno para contrarrestar dicho efecto.

- Realizar las pruebas de hipótesis correspondientes a la comparación de la media de crecimiento de las exportaciones del Ecuador hacia el mercado de los EEUU, respecto al resto de las series estudiadas.

El cumplimiento de los objetivos permitirá la determinación de una línea base para evaluar la efectividad de la política del Estado aplicada en este caso y a la vez establecer la validez o no de la misma como mecanismo a ser aplicado en futuras situaciones similares y de esta manera conseguir impactos positivos en diversos sectores exportadores del país, lo que redunda en beneficios a los productores y fomenta la generación de fuentes de trabajo, fortaleciendo de tal manera la economía nacional.

\section{Materiales y métodos}

Para cumplir con los objetivos planteados, se tomaron los registros del Banco Central del Ecuador (2017), el Banco de Guatemala (2017) y el Centro de Comercio Internacional (ITC) (2017), instituciones que proporcionaron la información respecto al valor de las exportaciones de brócoli ecuatorianas y guatemaltecas en el periodo en análisis, para luego establecer las comparaciones mediante el uso de un modelo matemático. 
El estudio tiene enfoque cuantitativo, porque se recolectó información correspondiente a la exportación hacia distintos mercados de la hortaliza en el Ecuador y Guatemala, para determinar el impacto de la medida gubernamental que eliminó la exención arancelaria de que gozaba ese producto en el mercado de los EEUU.

Inicialmente se definieron las variables de estudio de la investigación y luego se indagaron los datos correspondientes a cada una de ellas para lo cual se investigó en los servicios de información estadística de las páginas WEB de las instituciones antes mencionadas el valor de las siguientes series de datos, cada serie coincidente con cada una de las variables a estudiar:

1. Exportaciones de brócoli del Ecuador con destino a EEUU durante el período 2010 - 2016. 2. Exportaciones de brócoli del Ecuador con destino a Japón durante el período 2010 - 2016.

3. Exportaciones de brócoli del Ecuador al resto del mundo durante el período 2010 - 2016.

4. Exportaciones de brócoli de Guatemala con destino a EEUU durante el período 2010 2016.

Basados en la técnica de la observación directa se procedió a tabular la información recolectada mediante la elaboración de registros realizados por los autores que permitan establecer las comparaciones y realizar los análisis que más adelante se describen. Asimismo, se elaboraron gráficos analíticos con las exportaciones ecuatorianas y guatemaltecas de brócoli a los EEUU y con las exportaciones del Ecuador de esta hortaliza a los mercados estadounidense, japonés y del resto de los países.

Posteriormente se calcularon los coeficientes de correlación entre las series de datos correspondientes a las exportaciones de brócoli del Ecuador y Guatemala a EEUU y entre las exportaciones de brócoli del Ecuador hacia EEUU respecto a Japón y resto del mundo. Se determinaron, asimismo, las rectas de mejor ajuste de cada una de las series de datos en los gráficos correspondientes con el fin de determinar las tendencias de cada serie.

Utilizando el método descriptivo se estableció la relación concerniente a la evolución de cada variable y se realizaron las comparaciones entre las mismas para, a través del análisis deductivo, determinar si la estrategia gubernamental adoptada para contrarrestar la aplicación de aranceles a este producto fue efectiva, la cual podría considerarse eficaz si se comprueba que la salida del ATPDEA no afectó la tendencia de las exportaciones de brócoli a los EEUU comparadas con la tendencia de las mismas respecto al principal mercado de este producto que es Japón y con el resto del mundo, partiendo de que la afectación por la pérdida de exenciones arancelarias solo ocurrió en el mercado de los EEUU.

El otro aspecto a probar para corroborar la eficacia de la política pública aplicada en este caso será analizar la evolución de las exportaciones ecuatorianas de la hortaliza al mercado norteamericano comparándolas con el comportamiento de las correspondientes a Guatemala, un país que goza de preferencias arancelarias en el mercado de EEUU gracias al Tratado de Libre Comercio entre Estados Unidos y Centroamérica (CAFTA, por sus siglas en inglés Central America Free Trade Agreement). 
Teniendo en cuenta los puntos a comprobar antes descritos, se procedió a elaborar las hipótesis nulas y alternativa de la presente investigación:

- Hipótesis nula (Ho): El abandono del tratado ATPDEA por parte del gobierno del Ecuador no causó afectación significativa a las exportaciones de brócoli ecuatoriano al mercado de los EEUU respecto a las exportaciones de la hortaliza a otros mercados y a las exportaciones del mismo renglón realizadas por Guatemala al mismo mercado.

- Hipótesis alternativa (H1): El abandono del tratado ATPDEA por parte del gobierno del Ecuador causó afectación significativa a las exportaciones de brócoli ecuatoriano al mercado de los EEUU respecto a las exportaciones de la hortaliza a otros mercados y a las exportaciones del mismo renglón realizadas por Guatemala al mismo mercado.

Para probar las hipótesis planteadas se procederá a aplicar la prueba de hipótesis utilizando la distribución $\mathrm{t}$ ( $\mathrm{n}<30 ; 7$ observaciones), partiendo de que se desconoce la desviación estándar de las poblaciones y suponiendo que éstas son normales o aproximadamente normales. Se aceptará $\mathrm{H}_{0}$ si la media de crecimiento de las exportaciones de brócoli ecuatorianas al mercado de $\operatorname{EEUU}(\mu)$, es mayor o igual a la media de crecimiento de las exportaciones al mercado de Japón $\left(\mu_{1}\right)$, al resto de los mercados $\left(\mu_{2}\right)$ y, respecto también, a las exportaciones de Guatemala al mercado de los $\operatorname{EEUU}\left(\mu_{3}\right)$.

Por tanto: $\quad \mathbf{H}_{0}: \boldsymbol{\mu} \geq \boldsymbol{\mu}_{1} ; \boldsymbol{\mu}_{2} ; \boldsymbol{\mu}_{3}$ $\mathrm{H}_{1}: \mu<\mu_{1} ; \mu_{2} ; \mu_{3}$

Para dar cumplimiento a los objetivos específicos mediante los lineamientos expresados en presente sección de metodología, se relacionan los siguientes materiales y equipos que fueron requeridos durante el proceso investigativo:

- Suministros de oficina y de computación.

- Equipos de computación.

- Registros del BCE de las exportaciones de brócoli ecuatorianas hacia los EEUU, Japón y resto del mundo del periodo 2010 - 2016.

- Registros del Banco de Guatemala de las exportaciones de brócoli de ese país a los EEUU, durante el periodo 2010 - 2016.

- Información de artículos de prensa y revistas relativas a la temática abordada.

\section{Resultados}

El análisis de la información proporcionada por el Banco Central del Ecuador (2017) a partir de los registros de las exportaciones de brócoli ecuatorianas a los EEUU, Japón y resto del mundo durante el período 2010 - 2016, evidenció los resultados que se describen a continuación.

Durante el período analizado se constató que las exportaciones de brócoli del Ecuador al resto del mundo mantuvieron una tendencia decreciente en general, según se observa por la pendiente negativa de la recta de mejor ajuste calculada para esta serie de datos, recta que mostró un muy bajo coeficiente de ajuste $\mathrm{R}^{2}$ de 0,15 lo que no permite establecer concluyentemente una 
tendencia decreciente sino más bien irregular si nos remitimos al análisis de los porcentajes de crecimiento/decrecimiento de la serie (Ver Gráfico No. 2). De hecho, la media de crecimiento/decrecimiento anual de las exportaciones de brócoli al resto del mundo para el período de estudio se ubicó en un -0,04\% (Ver Tabla No. 2).

Las exportaciones al mercado japonés, el más importante y que no ha sufrido eliminación de aranceles para el brócoli, se comportaron con tendencia creciente sostenida confirmada por la pendiente positiva de la recta de mejor ajuste, la que asimismo reveló un alto coeficiente de ajuste $\mathrm{R}^{2}$ de 0,97 (Ver Gráfico No. 2). El promedio anual de incremento de las exportaciones a este destino fue de un notable 19,00\% (Ver Tabla No. 2).

Cuando se analizó la tendencia para el mercado estadounidense se comprobó similar comportamiento de tendencia creciente, si bien no tan sostenido como el caso japonés, confirmado por la pendiente también positiva de la recta que mejor ajusta la serie con un buen coeficiente $\mathrm{R}^{2}$ de 0,84 (Ver Gráfico No. 2). Por su parte, estas exportaciones crecieron como media anual durante el período 2010 - 2016 un 8,89\% (Ver Tabla No. 1).

La salida del tratado ATPDEA tuvo lugar en Jul/2013 y hasta Dic/2016 no se había incorporado aún el brócoli junto a otros renglones al Sistema General de Preferencias (SGP), tal y como se expone en El Telégrafo (2016) por lo cual hasta el cierre del período abordado en la presente investigación no se habían recuperado las preferencias arancelarias para la entrada del brócoli a los EEUU,

Dado esto se realizó una valoración específica de la evolución de las variables de estudio en el período 2013 - 2016, constatándose que, respecto a las exportaciones a los EEUU es solo el año 2013, coincidiendo con la pérdida de la exención arancelaria, cuando se registra una significativa caída de las exportaciones ascendente a $-11,48 \%$ respecto al año anterior, ya en el 2014 se registra, de inmediato una rápida recuperación del 18,77\% alcanzándose el mayor valor absoluto de exportaciones de todo el período hasta ese año, en los siguientes años 2015 y 2016 se mantuvo un crecimiento sostenido (Ver Tabla No. 1).

Al realizar similar análisis a las exportaciones hacia el Japón se comprobó que es también el año 2013 cuando único se registra un decrecimiento, pero este es muy reducido, de un -0,21\%, lo que obviamente obedece más probablemente a una situación casual que a una situación de causalidad lo cual sí se hace más evidente en el caso de las exportaciones a los EEUU (Ver Tabla No. 2).

Asimismo, se ejecutó el análisis de correlación entre las series de datos correspondientes a las exportaciones al resto del mundo respecto a las exportaciones a los EEUU y a las hechas con destino al mercado japonés (Ver Tabla No. 3). En el primer caso se obtuvo un coeficiente de correlación de -0,11 y en el segundo de -0,34, en ambos casos correlaciones negativas y débiles. Dado que la correlación no implica necesariamente una relación de causalidad a partir de que puede haber terceras variables involucradas, sumado al hecho de la debilidad de las correlaciones entre las variables involucradas, podemos establecer la no existencia de correlación entre ellas. 
Por su parte, al correlacionar las exportaciones ecuatorianas de la hortaliza a los mercados de los EEUU y Japón (Ver Tabla No. 3), hallamos que el coeficiente de correlación fue de 0,95 lo que indica una fuerte correlación positiva de la que puede deducirse que la imposición de aranceles a las exportaciones hacia EEUU desde mediados 2013 no constituyó una variable que determinó una diferencia significativa en cuanto a la evolución de ambas series de datos.

Con el fin de verificar desde otro punto de vista la eficacia de la política pública diseñada para apoyar a los exportadores de brócoli al mercado norteamericano se procedió a comparar la evolución de las exportaciones ecuatorianas con las de Guatemala que es uno de los principales proveedores latinoamericanos de la hortaliza al mercado de EEUU y disfruta de beneficios arancelarios a partir de pertenecer al tratado de libre comercio CAFTA.

En este caso se aprecia cómo los desempeños de ambas series de datos tienen un coeficiente de correlación de -0,60 que se califica como negativa y ligeramente fuerte (Ver Tabla No. 3), lo que es fácilmente apreciable a partir de que mientras que la tendencia de las exportaciones del Ecuador es claramente creciente las guatemaltecas son francamente decrecientes lo que se corrobora con la pendiente negativa de la recta de mejor ajuste que, sin embargo, no presenta un alto coeficiente $\mathrm{R}^{2}$ pues éste es de 0,48 (Ver Gráfico No. 1); a pesar de ello la tendencia mencionada es obvia visualmente lo que se refuerza cuando revisamos la evolución anual de la variable, la cual muestra caídas sostenidas desde el 2012 hasta el 2016 con un decrecimiento acumulado de $-62,06 \%$ entre esos años (Ver Tabla No. 1).

Al proceder a realizar las pruebas de hipótesis para cada caso se obtiene lo siguiente:

- Prueba para las medias de las exportaciones de brócoli ecuatoriano al mercado de EEUU ( $\mu$ ) y al mercado de Japón $\left(\mu_{1}\right)$. (Ver Tabla No. 4)

Valor crítico: $\quad-1,812461$

Estadístico t: $\quad-1,366364$

El estadístico t se ubica dentro de la zona de aceptación de $\mathrm{H}_{0}$, por tanto, se puede afirmar que el abandono del tratado ATPDEA por parte del gobierno del Ecuador no causó afectación significativa a las exportaciones de brócoli ecuatoriano al mercado de los EEUU respecto a las exportaciones de la hortaliza al mercado japonés.

- Prueba para las medias de las exportaciones de brócoli ecuatoriano al mercado de EEUU $(\mu)$ y al resto del mundo $\left(\mu_{2}\right)$. (Ver Tabla No. 5)

Valor crítico: $\quad-1,812461$

Estadístico t: $\quad 1,275579$

El estadístico t se ubica dentro de la zona de aceptación de $\mathrm{H}_{0}$, por tanto, se puede afirmar que el abandono del tratado ATPDEA por parte del gobierno del Ecuador no causó afectación significativa a las exportaciones de brócoli ecuatoriano al mercado de los EEUU respecto a las exportaciones de la hortaliza al resto del mundo.

- Prueba para las medias de las exportaciones de brócoli ecuatoriano al mercado de EEUU

$(\mu)$ y de las guatemaltecas al mismo mercado $\left(\mu_{3}\right)$. (Ver Tabla No. 6)

Valor crítico: $\quad-1,894578$

Estadístico t: $\quad 0,971557$

El estadístico t se ubica dentro de la zona de aceptación de $\mathrm{H}_{0}$, por tanto, se puede afirmar que el abandono del tratado ATPDEA por parte del gobierno del Ecuador no causó afectación 
significativa a las exportaciones de brócoli ecuatoriano al mercado de los EEUU respecto a las exportaciones de Guatemala a igual mercado.

Tabla No. 1: Exportaciones de Brócoli a EEUU (2010 - 2016).

(FOB en miles de USD)

\begin{tabular}{lrrrr}
\hline \multirow{2}{*}{ Años } & \multicolumn{2}{c}{ Guatemala } & \multicolumn{2}{c}{ Ecuador } \\
\cline { 2 - 5 } & Exportaciones & Variación & Exportaciones & Variación \\
$\mathbf{2 0 1 0}$ & $\$ 24.404,38$ & & $\$ 17.137,21$ & \\
$\mathbf{2 0 1 1}$ & $\$ 35.287,83$ & $44,60 \%$ & $\$ 18.309,68$ & $6,84 \%$ \\
$\mathbf{2 0 1 2}$ & $\$ 40.394,76$ & $14,47 \%$ & $\$ 20.704,04$ & $13,08 \%$ \\
$\mathbf{2 0 1 3}$ & $\$ 23.670,01$ & $-41,40 \%$ & $\$ 18.326,80$ & $-11,48 \%$ \\
$\mathbf{2 0 1 4}$ & $\$ 20.108,29$ & $-15,05 \%$ & $\$ 21.767,20$ & $18,77 \%$ \\
$\mathbf{2 0 1 5}$ & $\$ 16.772,77$ & $-16,59 \%$ & $\$ 26.268,40$ & $20,68 \%$ \\
$\mathbf{2 0 1 6}$ & $\$ 15.326,82$ & $-8,62 \%$ & $\$ 27.697,90$ & $5,44 \%$ \\
Prom. & & $\mathbf{- 3 , 7 7 \%}$ & & $\mathbf{8 , 8 9 \%}$ \\
\hline
\end{tabular}

Fuente: Banco Central del Ecuador, 2017; Banco de Guatemala, 2017.

Elaborado por: Los autores.

(FOB en miles de USD)

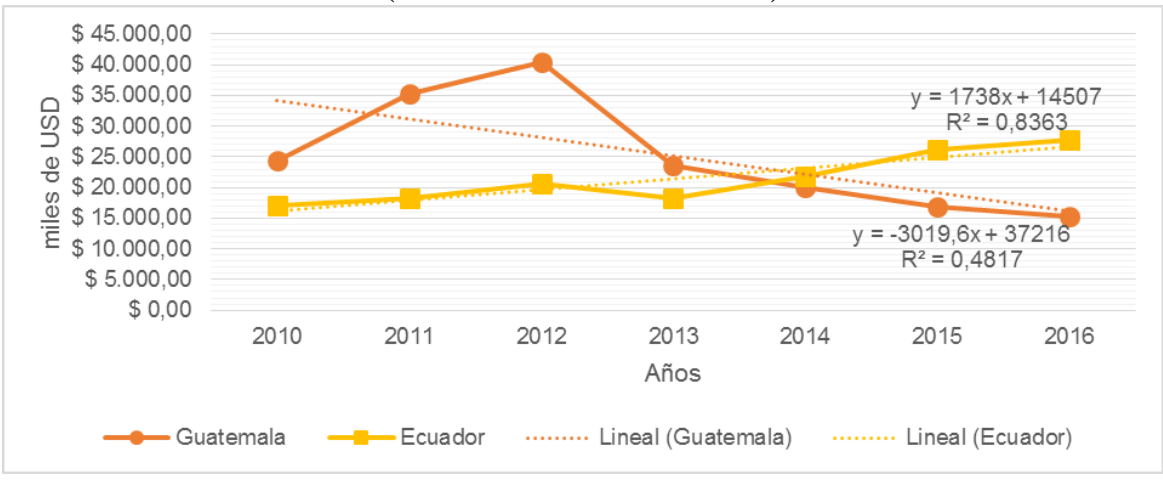

Gráfico No. 1: Exportaciones de Brócoli a EEUU (2010 - 2016).

Fuente: Banco Central del Ecuador, 2017; Banco de Guatemala, 2017.

Elaborado por: Los autores.

Tabla No. 2: Exportaciones de Brócoli del Ecuador (2010 - 2016). (FOB en miles de USD)

\begin{tabular}{lrrrr}
\hline Años & \multicolumn{2}{c}{ A Japón } & \multicolumn{2}{c}{ Resto del mundo } \\
\cline { 2 - 5 } & Exportaciones & Variación & Exportaciones & Variación \\
$\mathbf{2 0 1 0}$ & $\$ 12.322,69$ & & $\$ 28.599,46$ & \\
$\mathbf{2 0 1 1}$ & $\$ 16.485,82$ & $33,78 \%$ & $\$ 32.654,43$ & $14,18 \%$ \\
$\mathbf{2 0 1 2}$ & $\$ 22.245,29$ & $34,94 \%$ & $\$ 26.832,09$ & $-17,83 \%$ \\
$\mathbf{2 0 1 3}$ & $\$ 22.199,00$ & $-0,21 \%$ & $\$ 23.998,10$ & $-10,56 \%$ \\
$\mathbf{2 0 1 4}$ & $\$ 24.985,20$ & $12,55 \%$ & $\$ 25.785,00$ & $7,45 \%$ \\
$\mathbf{2 0 1 5}$ & $\$ 30.473,60$ & $21,97 \%$ & $\$ 28.236,40$ & $9,51 \%$ \\
$\mathbf{2 0 1 6}$ & $\$ 33.810,70$ & $10,95 \%$ & $\$ 27.391,00$ & $-2,99 \%$ \\
Prom. & & $\mathbf{1 9 , 0 0 \%}$ & & $\mathbf{- 0 , 0 4 \%}$ \\
\hline
\end{tabular}


Fuente: Banco Central del Ecuador, 2017.

Elaborado por: Los autores.

(FOB en miles de USD)

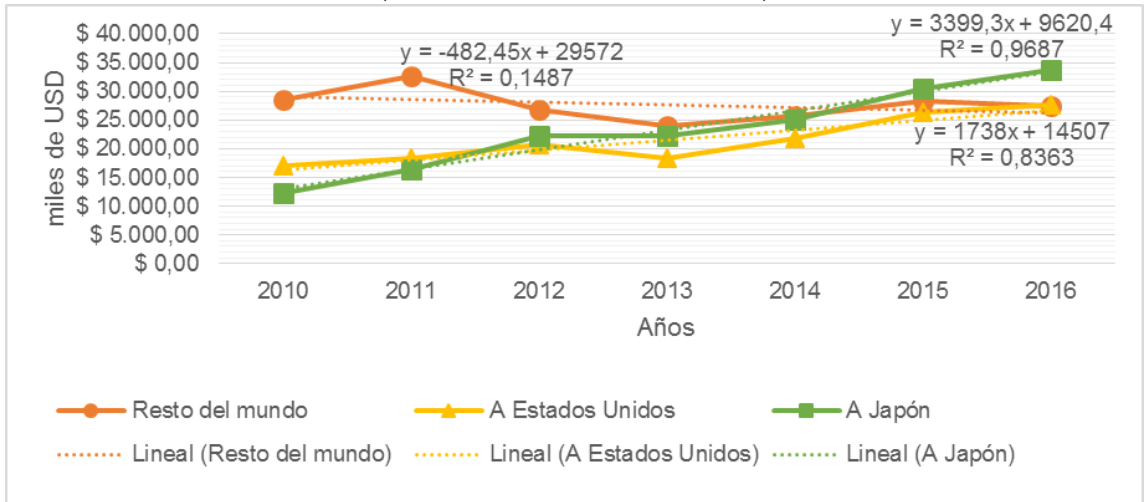

Gráfico No. 2: Exportaciones de Brócoli del Ecuador (2010 - 2016).

Fuente: Banco Central del Ecuador, 2017.

Elaborado por: Los autores.

Tabla No. 3: Correlaciones $(2010-2016)$.

\begin{tabular}{lr}
\hline Series de datos correlacionadas & Coef. de correlación \\
\hline Exportaciones de brócoli al mercado de Japón respecto al & 0,95 \\
mercado de EEUU & $-0,11$ \\
Exportaciones de brócoli al resto del mundo respecto a & $-0,34$ \\
exportaciones al mercado de EEUU & $-0,60$ \\
Exportaciones de brócoli al resto del mundo respecto a \\
exportaciones al mercado de Japón \\
$\quad$ Exportaciones de brócoli al mercado de los EEUU del Ecuador \\
respecto a las de Guatemala
\end{tabular}

Fuente: Banco Central del Ecuador, 2017; Banco de Guatemala, 2017.

Elaborado por: Los autores.

Tabla No. 4: Prueba t para las medias de crecimiento/decrecimiento de las exportaciones del Ecuador a los EEUU y al Japón.

\begin{tabular}{lrr}
\hline & $\boldsymbol{A} \boldsymbol{E E U U}$ & A Japón \\
\hline Media & 0,08888316 & 0,18996748 \\
Varianza & 0,0137055 & 0,01913316 \\
Observaciones & 6 & 6 \\
Diferencia hipotética de las medias & 0 & \\
Grados de libertad & 10 & \\
Estadístico t & $-1,36636482$ & \\
$\mathbf{P}(\mathbf{T}<=\mathbf{t})$ una cola & 0,10087991 & \\
Valor crítico de t (una cola) & 1,81246112 & \\
\hline
\end{tabular}

Fuente: Banco Central del Ecuador, 2017.

Elaborado por: Los autores.

Tabla No. 5: Prueba t para las medias de crecimiento/decrecimiento de las exportaciones del Ecuador a los EEUU y al resto del mundo. 


\begin{tabular}{lrr}
\hline & A EEUU & Otros países \\
\hline Media & 0,088883161 & $-0,000424252$ \\
Varianza & 0,013705504 & 0,015705596 \\
Observaciones & 6 & 6 \\
Diferencia hipotética de las medias & 0 & \\
Grados de libertad & 10 & \\
Estadístico t & 1,275579394 & \\
$\mathbf{P}(\mathbf{T}<=\mathbf{t})$ una cola & 0,115469121 & \\
Valor crítico de t (una cola) & 1,812461123 & \\
\hline
\end{tabular}

Fuente: Banco Central del Ecuador, 2017.

Elaborado por: Los autores.

Tabla No. 6: Prueba t para las medias de crecimiento/decrecimiento de las exportaciones del Ecuador a los EEUU y de Guatemala a los EEUU.

\begin{tabular}{lrr}
\hline & Ecu-EEUU & Gua-EEUU \\
\hline Media & 0,088883161 & $-0,037651149$ \\
Varianza & 0,013705504 & 0,088067002 \\
Observaciones & 6 & 6 \\
Diferencia hipotética de las medias & 0 & \\
Grados de libertad & 7 & \\
Estadístico t & 0,971557902 & \\
P(T<=t) una cola & 0,181818484 & \\
Valor crítico de $\mathbf{t}$ (una cola) & 1,894578605 & \\
\hline
\end{tabular}

Fuente: Banco Central del Ecuador, 2017; Banco de Guatemala, 2017.

Elaborado por: Los autores.

\section{Discusión}

La discusión de los resultados obtenidos se realiza mediante el análisis de los criterios de los expertos acerca del pronóstico de las afectaciones que para la exportación del brócoli al mercado de los EEUU traería la ruptura del ATPDEA, así como, de las evidencias acerca del impacto sobre los exportadores posterior a la medida y los resultados de esta propia investigación. Al respecto se revisan los criterios a favor y en contra de esta medida económica del gobierno ecuatoriano:

- Según plantea el Ministerio de Coordinación de Política Económica (2011), las exportaciones petroleras, conjuntamente con las de flores, hortalizas (brócoli en primer término) y frutas serían los principales productos que se verían afectados por la pérdida de preferencias del ATPDEA, con una afectación añadida pues tampoco podrían ingresar bajo el programa SGP que también provee exenciones arancelarias a las importaciones norteamericanas. También plantea que "la pérdida de las preferencias significaría que el costo final del producto para el importador será mayor y los productos ecuatorianos perderían competitividad de precio en el mercado estadounidense".

- El diario El Comercio (2014) publicó que "tras un año sin preferencias arancelarias por parte de EE.UU. el sector exportador ecuatoriano lucha contra las consecuencias de esta 
situación”, más adelante expone que "para evitar el impacto de esta situación en el sector privado, el Gobierno, a través de la Ley de Incentivos del Sector Productivo, puso a disposición de los exportadores los Certificados de Abono Tributario (CAT), que sirven para el pago de obligaciones tributarias, aduaneras o con la banca pública. En el mismo artículo se hace referencia a que "el CAT que se entrega a los exportadores corresponde a un valor equivalente al 100\% de aranceles pagados en EE.UU" y se entrevista a un exportador de flores que indica que "no ha tenido ningún problema para acceder al dinero del CAT y con ello ha podido pagar impuestos. Pero, además, evitado perder el mercado".

- Por su parte, Pasión por la democracia (2011), sentenció "al terminarse el Atpdea y no existir ningún avance en el tratado de libre comercio, la producción ecuatoriana quedará al margen del principal mercado del mundo".

- Citando a ECUADORINMEDIATO.com (2013) puede leerse que "Cristian Espinosa, presidente de la Cámara de Comercio Ecuatoriano-Americana, aseguró que, tras la terminación del ATPDEA, quien pagará el arancel de los productos ecuatorianos que llegan al mercado estadounidense será el importador de ese país. Por tanto, considera que a largo plazo el empresario norteamericano buscará proveedores de otros países "donde no tenga que pagar aranceles", dando lugar a la pérdida de competitividad de los exportadores ecuatorianos".

- Nathalie Cely, ex embajadora ecuatoriana en Washington, señaló, de acuerdo a El Telégrafo (2013), que "hay grupos empresariales que están alarmados por la extinción del Atpdea, y aceptó "no estar dejando de ver el problema, pero sí dimensionándolo", como respuesta a las voces de nerviosismo del país. La funcionaria dijo que "el país se encuentra preparado" para salir del ATPDEA y que existen estrategias nacionales enfocadas a exponer productos con valor agregado y ganar mercados en crecimiento".

- Según el Ministerio de Comercio Exterior (2013), el ex Ministro Coordinador de la Producción, Empleo y Productividad, Richard Espinosa expresó en rueda de prensa "es importante mencionar que el sector productivo tiene que estar tranquilo y no preocuparse, porque tenemos lista la nueva Ley de Abono Tributario. La reforma a esta respectiva ley que tiene como propósito permitir a través de certificados de abonos tributarios se compensen los beneficios que se venían recibiendo a través del ATPDEA que se estiman eran aproximadamente de 23 millones de dólares". Asimismo, se señala que "la Ley de Abono tributario es un mecanismo de compensación que permitirá que los productos que se benefician del mecanismo preferencial de aranceles bajo el sistema ATPDEA puedan recibir un apoyo a través de la concesión de un certificado de abono tributario por el monto de pago arancelario cuando el sistema expire. Esto se realizaría a través de un sistema ágil y efectivo, de tal manera se compensaría a todos los productos que se beneficiaban del ATPDEA”.

Teniendo en cuenta los diferentes criterios revisados se aprecia la opinión, previa a la salida del tratado ATPDEA, de que esta decisión lesionaría seriamente la competitividad de los productos exportables que ingresaban a EEUU bajo el citado tratado, lo cual sería lógico y cierto si el gobierno nacional no actuara en función de proteger estos renglones buscando mecanismos de compensación para evitar la caída de competitividad obvia que sufrirían los productos que perdieran las exenciones arancelarias. Otros criterios, sin embargo, establecen la efectividad de 
la aplicación de la política gubernamental ejecutada para contrarrestar los efectos negativos de la salida del ATPDEA.

En la presente investigación se pudo observar que en el año 2013 se registra la única caída en las exportaciones ecuatorianas de brócoli al mercado estadounidense de todo el período estudiado, lo que puede ser consecuencia de la incertidumbre generada por la medida, sin embargo ese mismo año también se afectan las exportaciones al primer mercado de esa hortaliza, que es Japón, y con el cual no existían previsibles dificultades, en el caso de las exportaciones de brócoli a otros destinos ya se acumulaba un -28,39\% de decrecimiento en dos años consecutivos. Asimismo, se comprobó que existe una fuerte correlación positiva entre las exportaciones al Japón y los EEUU, ambas con tendencias claramente crecientes durante los años analizados.

Si analizamos la evolución de las exportaciones de Guatemala del mismo renglón al mercado de EEUU, donde este producto sí ha gozado de exención arancelaria durante toda la etapa examinada, se puede constatar cómo las tendencias y correlaciones entre ambas variables son contrarias. Se aprecia, asimismo, que entre el 2013 y 2014 mientras que las exportaciones ecuatorianas se recuperan las guatemaltecas se desploman, a pesar de mantener las preferencias arancelarias.

En consecuencia, de los resultados obtenidos se manifiesta que, si bien existió un efecto negativo, atribuible a la eliminación de la ATPDEA por parte del gobierno ecuatoriano, que impactó en la tendencia de las exportaciones ecuatorianas de brócoli en el propio año 2013, puede comprobarse, sin embargo, que la recuperación este sector productivo nacional fue inmediata, retomando su crecimiento en el 2014 y siendo más exitoso incluso que el desempeño de las exportaciones de brócoli guatemaltecas, uno de los mayores exportadores de la región, lo que puso de manifiesto que este efecto no fue tan adverso como lo pronosticaron en algún momento los representantes de varios sectores productivos del país, lo que se logró gracias al efectivo resultado de la política del Gobierno Nacional aplicada a este propósito a través de los CAT que, al compensar a los exportadores por el costo de los aranceles a pagar por sus productos, permitieron que no perdieran competitividad frente al mercado de los EEUU.

\section{Conclusiones}

Las exportaciones de brócoli del Ecuador a los EEUU en el periodo 2010 - 2016, tuvieron una tendencia creciente, solo hay un año que registra una caída, el 2013 coincidiendo con la ruptura del ATPDEA por parte del gobierno, recuperándose inmediatamente al año siguiente y volviendo a sostener el crecimiento en los años posteriores. De manera muy similar se comportaron las exportaciones al mercado más importante de la hortaliza, el de Japón, no afectado por la salida del ATPDEA. De tal manera, que se observa que la salida del ATPDEA aunque puede haber generado perjuicio, éste fue momentáneo registrándose una pronta y sólida recuperación, atribuible a la política gubernamental diseñada al respecto.

En cuanto a las exportaciones de brócoli de Guatemala en el mismo periodo, la tendencia, a diferencia del caso ecuatoriano, fue creciente entre 2010 y 2012 pero a partir de este último año se aprecia un notable y sostenido decrecimiento a pesar de que, también de manera distinta a 
Ecuador, la hortaliza guatemalteca disfruta de las exenciones arancelarias que comporta la pertenencia de ese país al CAFTA.

Esto conduce a concluir que la ruptura del ATPDEA ejerció una momentánea afectación a las exportaciones de brócoli al mercado estadounidense, donde pudieron incidir también otras causales, comprobándose además que el sector pudo recuperarse de manera inmediata, manteniendo la competitividad respecto a Guatemala, uno de sus principales rivales en la misma área geográfica y mercado, siendo la estrategia pública implementada el factor decisivo que contribuyó a la no pérdida de competitividad y, por consiguiente, de mercados.

\section{Bibliografía}

Banco Central del Ecuador. (2017). Estadísticas de Comercio Exterior. Obtenido de Banco Central del Ecuador: Sector Externo: https://www.bce.fin.ec/index.php/component/k2/item/762

Banco de Guatemala. (2017). Series Históricas. Obtenido de Estadísticas Macroeconómicas. Comercio Exterior (Exportaciones / Importaciones): http://www.banguat.gob.gt/inc/main.asp?id=111475\&aud=1\&lang=1

Cámara de Industrias y Producción. (2011). Efecto del ATPDEA en las exportaciones ecuatorianas. Obtenido de Revista Judicial derechoecuador.com: http://www.derechoecuador.com/articulos/detalle/archive/doctrinas/derechotributario/2011/0 5/03/efecto-del-atpdea-en-las-exportaciones-ecuatorianas

Centro de Comercio Internacional (ITC). (2017). TradeMap: Análisis e Investigación de Mercados. Obtenido de Centro de Comercio Internacional (ITC): http://www.trademap.org/Index.aspx

ECUADORINMEDIATO.com. (2013). ATPDEA: A largo plazo, importadores estadounidenses reemplazarán a proveedores ecuatorianos por otros, según Cristian Espinosa. Obtenido de Ecuadorinmediato.com: http://www.ecuadorinmediato.com/index.php?module=Noticias\&func=news_user_view\&id= 202013

ECUADORINMEDIATO.com. (2013). Ley Económica Urgente compensará al sector empresarial por salida del ATPDEA, asegura Presidente Correa. Obtenido de ECUADORINMEDIATO.com:

http://www.ecuadorinmediato.com/index.php?module=Noticias\&func=news_user_view\&id= 199863

Ecuavisa. (27 de Junio de 2013). ¿Qué es exactamente el Atpdea? Obtenido de Ecuavisa: http://www.ecuavisa.com/articulo/noticias/actualidad/34199-que-es-exactamente-el-atpdea

Ekos. (30 de 04 de 2013). El Impacto de la ATPDEA. Obtenido de Ekos: http://www.ekosnegocios.com/negocios/verArticuloContenido.aspx?idArt=2007

El Comercio. (24 de 07 de 2013). Ecuador sin Atpdea. Obtenido de El Comercio: http://www.elcomercio.com/opinion/ecuador-atpdea.html 
El Comercio. (2014). Un año sin Atpdea sí impactó en los exportadores. Obtenido de El Comercio: http://www.elcomercio.com/actualidad/atpdea-exportadores-comercio-arancelesecuador.html

El Telégrafo. (2013). El brócoli genera 5.000 empleos directos. Obtenido de El Telégrafo: http://www.eltelegrafo.com.ec/noticias/economia/8/el-brocoli-genera-5-000-empleos-directos

El Telégrafo. (2013). No más Atpdea. Correa plantea una ley como alternativa. Obtenido de El Telégrafo: http://www.eltelegrafo.com.ec/noticias/economia/8/no-mas-atpdea-correa-planteauna-ley-como-alternativa

El Telégrafo. (2016). Ecuador solicita agregar cuatro productos en el SGP. Obtenido de El Telégrafo: http://www.eltelegrafo.com.ec/noticias/economia/8/ecuador-solicita-agregar-cuatroproductos-en-el-sgp

Falconí, F., \& Oleas, J. (2013). Adiós Atpdea (Ley De Promoción Comercial Andina Y Erradicación De Drogas): No Es Una Mala Noticia. Obtenido de La línea de fuego. Pensamiento Crítico: https://lalineadefuego.info/2013/07/01/adios-atpdea-ley-de-promocion-comercial-andina-yerradicacion-de-drogas-no-es-una-mala-noticia-por-fander-falconi-y-julio-oleas/

Ministerio de Comercio Exterior. (2013). Compensaciones a exportadores. Obtenido de Ministerio de Comercio Exterior: http://www.comercioexterior.gob.ec/noticia-4/

Ministerio de Comercio Exterior. (2017). Japón Es El Principal Mercado Del Brócoli Ecuatoriano. Obtenido de Ministerio de Comercio Exterior: http://www.comercioexterior.gob.ec/japon-esel-principal-mercado-del-brocoli-ecuatoriano/

Ministerio de Coordinación de Política Económica. (2011). Costo arancelario de la no renovación del ATPDEA y del sistema general de preferencias para el Ecuador. Obtenido de Universidad Ecotec: http://www.ecotec.edu.ec/material/material_2012E_ECO350_21_20814.pdf

Pasión por la democracia. (2011). El Atpdea para Ecuador llegó a su fin. Obtenido de pasión por la democracia.com: http://pasionporlademocracia.com/el-atpdea-para-ecuador-llego-a-su-fin/

PROECUADOR. (2014). Brócoli: Segundo producto no tradicional más importante de la Sierra ecuatoriana. Obtenido de PROECUADOR: http://www.proecuador.gob.ec/2014/02/07/brocoli-segundo-producto-no-tradicional-masimportante-de-la-sierra-ecuatoriana/

PROECUADOR. (2017). Agroindustria. Obtenido de PROECUADOR: http://www.proecuador.gob.ec/compradores/oferta-exportable/agroindustria/ 